\title{
Syphilis and a pregnant woman: a real danger for the woman and the child
}

\author{
Katarzyna Plagens-Rotman ${ }^{1}$, Renata Przybylska², Katarzyna Gerke ${ }^{3}$, Małgorzata Piskorz-Szymendera ${ }^{1}$, \\ Magdalena Tomaszewska ${ }^{1}$, Anna Sadowska-Przytocka ${ }^{3}$, Zygmunt Adamski ${ }^{3}$, Magdalena Czarnecka-Operacz ${ }^{3}$
}

\begin{abstract}
'Department of Mother's and Child's Health, Poznan University of Medical Sciences, Poznan, Poland 2Department of Neurological Nursing, Poznan University of Medical Sciences, Poznan, Poland ${ }^{3}$ Department of Dermatology, Poznan University of Medical Sciences, Poznan, Poland
\end{abstract}

Adv Dermatol Allergol 2019; XXXVI (1): 119-124 DOI: https://doi.org/10.5114/ada.2019.82833

Syphilis is one of the sexually transmitted infections (STI) caused by Treponema pallidum of the Spirochaetaceae family, which is a Gram-negative bacterium measuring between $10-13 \mu \mathrm{m}$ and $0.15 \mu \mathrm{m}$ in diameter. Their characteristic feature is a rotational, forward and twisting movement observed in the macroanalysis. What is more, they are sensitive to dryness, high temperature, and antiseptics. Infection with Treponema pallidum is caused by the bacteria passing through the damaged mucous membrane, soft tissue mucosa, as well as directly getting into the bloodstream. The most common route of infection is a sexual intercourse, both oral and rectal [1-3]. Crucially, a transmission of the infection from the infected woman to the foetus is possible.

The World Health Organization (WHO) estimates that every year 1.5 million pregnant women are diagnosed with Treponema infections, whereas 520000 present complications, such as intrauterine foetal death, low birth weight, and congenital syphilis in neonates [4]. In Poland, in 2011, syphilis was diagnosed in 13 women during pregnancy and delivery. In comparison, positive serum reactions were observed in 22 pregnant women [5].

The International Union against Sexually Transmitted Infections recommends syphilis screening tests in all pregnant women during the first prenatal appointment [6]. However, in Poland it is obligatory to perform the tests up to the 10 weeks of gestation, and between $33-37^{\text {th }}$ week in the high-risk patient group [7].

Syphilis includes a wide range of clinical symptoms, and is characterized by a long-term and multi-stage course. In general, there are two types of syphilis: acquired (Latin: lues acquisita) and congenital (Latin: lues congenita).

Primary syphilis (Latin: lues primaria) - 3-9 weeks a painless, single, round or oval primary lesion appears in the area where Treponema pallidum entered the organism. It is characterized by smooth edges and a cartilaginous base. Additionally, the enlargement of the surrounding lymph nodes appears.

The most common site of primary lesions in women is the labia, cervix uteri, vaginal mucosa, or the genital area. However, atypical sites include the vermilion border of the lips, buccal mucosa, the tongue and the tonsils $[2,8,9]$.

Secondary syphilis (Latin: lues secundaria) - 9 weeks until the end of the $2^{\text {nd }}$ year following the initial infection - is characterized by the appearance of skin and mucosal lesions, as well as by the lymph nodes enlargement. In addition, rare symptoms include interstitial hepatitis, kidney and musculoskeletal lesions. In the laboratory tests, the abnormalities include increased leucocytosis, erythrocyte sedimentation rate (ESR), hypochromic anaemia, whereas in the cerebrospinal fluid analysis, positive serum reaction is noted which suggests the nervous system infection.

Early secondary syphilis - the most characteristic feature is the appearance of a syphilitic exanthema, where the most frequent manifestation is roseola - the lesions are of equal size, and emerge symmetrically along the trunk and anterior aspect of the upper extremities.

Secondary recurrent syphilis - recurrent roseolas, which are typical of this stage, are maculopapular, papular and pustular in character. They appear on the whole body surface; nevertheless, they emerge most frequently in the genital area, perineum, palms, feet, scalp and face. What is more, exuding papules may appear in the areas particularly susceptible to perspiration or mechanical injuries, such as the anus, inguinal regions, umbilical area and corners of the mouth which become enlarged and transform into condylomata lata [2, 3, 10, 11].

Address for correspondence: Katarzyna Plagens-Rotman MD, Department of Mother's and Child's Health, Poznan University of Medical Sciences, 41 Jackowskiego St, 60-512 Poznan, Poland, phone: +48 607165 279, e-mail: plagens.rotman@gmail.com Received: 27.07.2017, accepted: 13.12.2017. 
Tertiary syphilis (Latin: lues symptomatica tarda, lues tertiaria) - more than 2 years following the initial infection - the symptoms develop a few years after the infection and affect patients who did not undergo the treatment in the early stages, or cases where the therapy was insufficient. It most commonly affects the cardiovascular system (cardiovascular syphilis) or the nervous system (neurosyphilis).

Congenital syphilis (Latin: lues congenita) is the result of intrauterine foetal infection with Treponema pallidum from the infected pregnant mother. In the case of early syphilis, the infection risk is estimated at $70-100 \%$, whereas in terms of latent syphilis it is equal to $10 \%$. Most frequently, the infection occurs in 18-20 weeks of gestation [2, 3].

Early congenital syphilis symptoms may appear directly after birth or within the first weeks of life. They include:

- Early syphilis snuffles as a result of nasal mucosa ulceration;

- Vesicular eruption with spirochetes in the serous-purulent or serous-haemorrhagic fluid-filled vesicles, most commonly appearing on palms and feet;

$-80 \%$ of neonates are diagnosed with skeletal changes of the upper extremities, whereas 30\% present with Parrot's pseudoparalysis;

- Parrot's scars are a result of rupturing papules located around the lips, nose and anus;

- In terms of internal organs, the lesions include the liver (hepatomegaly), spleen (splenomegaly), lungs (white pneumonia, Latin: Pneumonia alba) and kidneys [2, 3].

Latent congenital syphilis is most commonly asymptomatic. However, about $20 \%$ of children are diagnosed with:

- Interstitial keratitis which is diagnosed at 5-30 years of age, and results in corneal transparency impairment and loss of vision;

- Hutchinson's teeth;

- Parrot's scars in the lip and anus area;

- Hearing impairment as a result of vestibulocochlear nerve damage;

- Mental retardation [12, 13].

The diagnosis of syphilis is based on the interview and physical examination, on direct examination visualizing Treponema pallidum in the tissues or skin, as well as on the indirect examinations which are aimed to detect Treponema pallidum antibodies in blood serum and the cerebrospinal fluid [14, 15].

Direct examinations in the diagnosis of syphilis:

- Dark field microscopy test of exuding lesions in primary and secondary syphilis;

- Polymerase chain reaction (PCR) as a method detecting spirochetes in tissues, cerebrospinal fluid and blood;

- Direct immunofluorescent assay in suspected syphilis and in cases when serum reaction test results are negative;
- Immunofluorescence assay;

- Immunohistochemical assay [2, 16].

Indirect examinations in the diagnosis of syphilis

[17-24]:

- Non-treponemal tests - positive test results are ob-

tained about 5-6 weeks after the primary lesion appearance:

- Venereal Diseases Research Laboratory test (VDRL),

- Rapid Plasma Reagin test (RPR),

- Toluidine Red Unheated Serum Test (TRUST);

- Treponemal tests - positive results are obtained within 1-2 weeks of the primary ulceration period:

- Treponema Pallidum Haemagglutination test (TPHA),

- Micro-Haemagglutination Assay for Treponema Pallidum (MHATP),

- Treponema Pallidum Passive Particle Agglutination test (TTPA),

- Fluorescent Treponemal Antibody Absorption test (FTA-ABS),

- Treponemal Enzyme Immunoassay (EIA),

- Chemiluminescence Immunoassay (CIA).

The purpose of the paper is to present 2 cases of pregnant women with the diagnosis of acquired syphilis treated at the Dermatology Chair and Clinic at the Obstetrics and Gynaecology Clinic at the University Hospital of Medical Sciences in Poznan.

Case 1: a 28-year-old patient was admitted to the Department of Dermatology at the University Hospital of Poznan University of Medical Sciences for the late latent syphilis treatment at 14 weeks' gestation of her $2^{\text {nd }}$ pregnancy. The patient gave a 4-year history of syphilis. Serum reactions tested positive on 2 July 2015 during pregnancy where VDRL was positive (1: 16 titre), with positive FTA-ABS and positive FTA (1: 450 titre), as well as positive PTHA ( 1 : 10240 titre).

In the course of treatment at the outpatient dermatology clinic, doxycycline of $100 \mathrm{mg}$ twice daily for 28 days was introduced both for the patient and her husband, which was followed by $2 \mathrm{~g}$ of azithromycin.

The last serum reaction check-up of 2 February 2016 revealed FTA-ABS 1 : 200 with RPR 1 : 80. During hospitalisation at the Department of Dermatology at the University Hospital of Poznan University of Medical Sciences in October 2015 the patient was treated with procaine penicillin in 2.4 million IU intramuscular injections. Additionally, the patient underwent ophthalmological tests which revealed significant myopia, as well as neurological tests where no abnormalities were detected. Moreover, a lumbar puncture was performed following computed tomography angiography which revealed a negative TPHA serum reaction.

The laboratory results indicated the following abnormalities: a slight decrease in haemoglobin $11.6 \mathrm{~g} / \mathrm{dl}$, as well as in haematocrit 32.6\%, elevated C-reactive protein (CRP) $10.8 \mathrm{mg}$ and ESR $49 \mathrm{~mm} / \mathrm{h}$, a slight increase in both fibrinogen $402 \mathrm{mg} / \mathrm{dl}$ and D-dimers $0.64 \mu \mathrm{g} / \mathrm{ml}$ 
FEU. Moreover, a penicillin test was performed, which was negative.

Benzathine benzylpenicillin was administered in a single 2.4 million IU intramuscular injection with good tolerance.

On 29 February 2016, the patient was discharged home in good general condition with the recommendation of follow-up hospitalisation on 4 March 2016 for the administration of benzathine benzylpenicillin, control CRP, ESR, CBC laboratory tests and further gynaecological supervision.

Preterm ultrasound scan: vertex position, cephalic presentation. Body weight $\pm 3000-3100$ g, placenta on the posterior uterine wall, FHR (+), R (+). BPD $9.4 \mathrm{~cm}=$ $38+6, \mathrm{HC} 33.9 \mathrm{~cm}=38+3, \mathrm{AC} 33.2 \mathrm{~cm}=37+2, \mathrm{FL} 7.2 \mathrm{~cm}$ $=36+2$.

In 39 week of pregnancy she gave birth to a female child in natural labour. The child birth weight: $3480 \mathrm{~g}$. Episiotomy and suturing of the wound following the episiotomy.

In the first and fifth minute, the newborn was rated at 10 points on the Apgar scale. $\mathrm{pH}$ of umbilical cord blood: 7.19 (-5.6) and 7.27 (-6.4). Physical examination: normal body composition, good nutritional status, pink skin, correct warmth. Symmetrical skull. Anterior fontanel: $1 \times 1 \mathrm{~cm}$, posterior fontanel: $0.3 \times 0.3 \mathrm{~cm}$. Complete palate, nose, ears, eyes unchanged. Correct collarbones. No skin lesions. Symmetrical chest, 40 breaths per minute - abdominal breathing. Correct vesicular murmur. Newborn heart activity: 140 beats per minute, clean tones. Soft abdomen, liver and spleen not enlarged. Palpable pulse in the extremities. Hip joints - normal. Physical activity, tension - normal. Symmetrical gripping and Moro responses. Nodule with sterile dressing. Patent anus.

After reading the results of laboratory tests (Table 1 ), the newborn was treated with penicillin 150,000 IU/kg of body weight for 2 weeks, by intravenous injection in 6 divided doses. In addition, necessary blood control: morphology, electrolytes, urea, and creatinine. Neonatal examination by an ophthalmologist - correct. On the $24^{\text {th }}$ day of life, the newborn was discharged home in good general condition with the recommendation of serologic control 3 months after completion of treatment (negative result). Proper development of the newborn.

Case 2: a 23-year-old patient at 20 weeks' gestation was admitted to the Department of Dermatology at the University Hospital of Poznan University of Medical Sciences following positive serum reactions to syphilis performed in an outpatient clinic with double positive USR and positive TPHA, no skin lesions and no symptoms suggesting syphilis diagnosis.

The patient reported miscarriage 3 years earlier at 20 weeks' gestation, with a negative USR test performed at the time. According to the patient, no abnormalities had been detected in the foetus; however, there was no documentation supporting the information. Moreover, the patient reported 5-miscarriages of her grandmother, one of her mother, periodic lower extremity oedema; nevertheless, no skin lesions or swellings were present on admission. Additionally, the patient gave a family history of allergy to penicillin of her grandmother and mother. Hence, for fear of an allergic reaction, the patient had not taken penicillin; moreover, she did not remember the antibiotics she had been prescribed in the past.

In the course of current hospitalisation, the laboratory tests showed large numbers of bacteria in the sample urine test; however, no leucocytosis, fever or dysuria were found; furthermore, D-dimers were elevated $1.42 \mu \mathrm{g} / \mathrm{ml} \mathrm{FEU}$, fibrinogen $416 \mathrm{mg} / \mathrm{dl}$, slightly shortened activated partial thromboplastin time (APTT) equal to $24 \mathrm{~s}$, prothrombin time (PT) of $11 \mathrm{~s}$, and international normalized time (INR) within the normal range, slightly elevated ESR $23 \mathrm{~mm} / \mathrm{h}$, CRP within the norm $0.4 \mathrm{mg} / \mathrm{l}$.

In the syphilis screening tests, including TPHA, the results were negative; however, RPR was positive. The results of Lyme disease IgM and IgG tests were also negative. Due to the suspected penicillin allergy, a test for $\beta$-lactam specific IgE was performed and the penicillin treatment was withheld. Prior to obtaining results, erythromycin was administered at the dose of $600 \mathrm{mg}$ 3 times daily, which was discontinued following negative syphilis laboratory tests and discomfort experienced by the patient (nausea).

Abdominal USG was done, which showed normal echogenic liver, of normal size, and no focal lesions. Moreover, it also revealed normal size bile duct, homogenous normal size spleen, as well as normal retroperitoneal space and isoechoic large abdominal vessels. Additionally, lymph nodes were of normal size, the urinary bladder was empty, and the kidneys were of normal structure and function without signs of stasis or concrements. The patient was pregnant, with the visible foetal heart rate.

The diagnostic tools included also the Nelson test (TPI), FTA-ABS, and TPHA - with negative results. Due to the suspected penicillin allergy, antigen specific IgE was determined; however, no elevation was found. Furthermore, antiphospholipid antibodies were measured with no abnormalities detected.

The patient was discharged in good general condition with the recommendation of an urgent gynaecological consultation, and decisions regarding further procedures, as well as of a syphilis test for the patient's sexual partners, and of dermatological control appointment in an outpatient clinic.

Preterm ultrasound scan: vertex position, cephalic presentation. Body weight $\pm 2939-3262$ g, placenta on the posterior uterine wall, FHR (+), R (+). BPD $91 \mathrm{~mm}(37+5), \mathrm{HC}$ $334 \mathrm{~mm}(37+4)$, AC $331 \mathrm{~mm}(37+1)$, FL $76 \mathrm{~mm}(38+6)$.

In 40 week of pregnancy she gave birth to a female child in natural labour. The child birth weight: 2920 g. In the first and fifth minute, the newborn was rated at 
K. Plagens-Rotman, R. Przybylska, K. Gerke, M. Piskorz-Szymendera, M. Tomaszewska, A. Sadowska-Przytocka, Z. Adamski, M. Czarnecka-Operacz

Table 1. Characteristics of laboratory tests performed in a newborn of the mother with acquired syphilis

\begin{tabular}{|c|c|c|c|c|c|}
\hline Blood morphology & First day of life & Second day of life & Seventh day of life & $\begin{array}{l}\text { Fourteenth day } \\
\text { of life }\end{array}$ & $\begin{array}{l}\text { Twenty first day } \\
\text { of life }\end{array}$ \\
\hline Leukocytes [G/l] & 16.22 & 19.83 & 14.36 & 14.05 & 10.95 \\
\hline Erythrocytes [T/I] & 5.20 & 4.65 & 4.44 & 4.46 & 4.14 \\
\hline Blood platelets [G/I] & 294.0 & 248.0 & 380.0 & 566.0 & 461.0 \\
\hline $\begin{array}{l}\text { Haemoglobin } \\
{[\mathrm{mmol} / \mathrm{l}]}\end{array}$ & 10.90 & 9.80 & 9.10 & 9.00 & 8.20 \\
\hline Haematocrit [l/l] & 0.484 & 0.424 & 0.397 & 0.394 & 0.365 \\
\hline $\begin{array}{l}\text { Mean volume of red } \\
\text { blood cell }[\mathrm{fl}]\end{array}$ & 93.10 & 91.20 & 89.40 & 88.30 & 88.20 \\
\hline $\begin{array}{l}\text { Mean corpuscular } \\
\text { haemoglobin [fmol] }\end{array}$ & 2.10 & 2.11 & 2.05 & 2.02 & 1.98 \\
\hline $\begin{array}{l}\text { Mean corpuscular } \\
\text { haemoglobin } \\
\text { concentration } \\
{[\mathrm{mmol} / \mathrm{l}]}\end{array}$ & 22.500 & 23.100 & 22.900 & 22.800 & 22.500 \\
\hline $\begin{array}{l}\text { Red blood cell } \\
\text { distribution width, } \\
\text { CV (\%) }\end{array}$ & 16.80 & 16.50 & 15.40 & 15.0 & 15.00 \\
\hline $\begin{array}{l}\text { Mean platelet } \\
\text { volume }[\mathrm{fl}]\end{array}$ & 10.8 & 11.1 & 11.5 & 12.0 & 12.2 \\
\hline $\begin{array}{l}\text { Granulocytes - } \\
\text { divided (\%) }\end{array}$ & 58 & & 20 & 3 & 27 \\
\hline $\begin{array}{l}\text { Granulocytes - } \\
\text { eosinophilic (\%) }\end{array}$ & 2 & & 3 & 6 & 6 \\
\hline Lymphocytes (\%) & 40 & & 67 & 46 & 60 \\
\hline $\begin{array}{l}\text { Alanine } \\
\text { aminotransferase } \\
{[\mathrm{U} / \mathrm{I}]}\end{array}$ & & 24.10 & 21.50 & 21.10 & 26.00 \\
\hline $\begin{array}{l}\text { Aspartate } \\
\text { aminotransferase } \\
{[\mathrm{U} / \mathrm{I}]}\end{array}$ & & 71.00 & 30.00 & 25.20 & 28.10 \\
\hline $\begin{array}{l}\text { C-reactive protein } \\
{[\mathrm{mg} / \mathrm{l}]}\end{array}$ & 0.12 & 8.81 & 2.21 & & 0.19 \\
\hline $\begin{array}{l}\text { Serum creatinine } \\
\text { [mg/dl] }\end{array}$ & & & 0.37 & 0.22 & 0.23 \\
\hline $\begin{array}{l}\text { Blood urea nitrogen } \\
{[\mathrm{mg} / \mathrm{dl}]}\end{array}$ & & & 6.30 & 8.30 & 5.30 \\
\hline Sodium [mmol/l] & & & 136.0 & 140.0 & 137.0 \\
\hline Potassium [mmol/l] & & & 5.9 & 5.9 & 5.5 \\
\hline Chlorides [mmol/l] & & & 98.2 & 102.0 & 102.3 \\
\hline Calcium [mmol/l] & & & 2.61 & 2.70 & 2.66 \\
\hline $\begin{array}{l}\text { Magnesium } \\
{[\mathrm{mmol} / \mathrm{l}]}\end{array}$ & & & 0.73 & 0.75 & 0.80 \\
\hline $\begin{array}{l}\text { Unlimited } \\
\text { phosphorus [mg/dl] }\end{array}$ & & & 7.01 & 6.82 & 6.68 \\
\hline RPR & Negative & & & & Negative \\
\hline FTA - ABS & $\begin{array}{l}\text { Positive (antibody } \\
\text { titres } 1: 50 \text { ) }\end{array}$ & & & & $\begin{array}{c}\text { Positive (antibody } \\
\text { titres } 1: 50 \text { ) }\end{array}$ \\
\hline TPHA & $\begin{array}{l}\text { Positive (antibody } \\
\text { titre } 1: 80 \text { ) }\end{array}$ & & & & $\begin{array}{c}\text { Positive (antibody } \\
\text { titre } 1: 80 \text { ) }\end{array}$ \\
\hline
\end{tabular}


10 points on the Apgar scale. $\mathrm{pH}$ of umbilical cord blood: 7.32 (-3.0) and 7.35 (-3.8). Physical examination: normal body composition, good nutritional status, pink skin, correct warmth. Symmetrical skull. Anterior fontanel: $1 \times$ $1 \mathrm{~cm}$, posterior fontanel: $0.3 \times 0.3 \mathrm{~cm}$. Complete palate, nose, ears, eyes unchanged. Correct collarbones. No skin lesions. Toxic erythema on the skin. Symmetrical chest, 40 breaths per minute - abdominal breathing. Newborn heart activity: 140 beats per minute, clean tones. In addition, physical examination revealed murmur over the heart without evidence of cardiovascular endurance (echo: 3 septal defects). Soft abdomen, liver and spleen not enlarged. Normal hip joints. Symmetrical gripping and Moro responses. Nodule with sterile dressing. Patent anus. No deviation in laboratory tests.

The newborn was discharged home on the $3^{\text {rd }}$ day of life in good general condition with the recommendation of cardiology control after 1 month. Proper development of the newborn.

It is estimated that $70-100 \%$ of neonates born by pregnant women with untreated syphilis will become infected, whereas intrauterine foetal death will occur in $30 \%$ of cases [23].

Benzathine benzylpenicillin in 2.4 million IU intramuscular injections are the first line of treatment in pregnant women diagnosed with early syphilis. Due to the lack of long-term penicillin in Poland, the recommended treatment is procaine penicillin at the dose of $600000 \mathrm{IU}$ daily for 14 days following the early syphilis treatment, and for 21 days in the late syphilis management.

In the case of positive penicillin test results or a refusal of treatment, it is recommended to administer erythromycin of $500 \mathrm{mg} 4$ times daily and doxycycline after the delivery, or to administer ceftriaxone in $500 \mathrm{mg}$ intramuscular injections for 10 days.

Following benzathine penicillin G injections, the patient should be supervised for 30 min.

Screening test for syphilis should be performed in the $1^{\text {st }}$ trimester of pregnancy (at 7-8 weeks of gestation), and in the $3^{\text {rd }}$ trimester (at 33-37 weeks gestation); Serology tests should be repeated in case of a high risk and local epidemiology.

Management of a neonate diagnosed with syphilis [25, 26]:

- In case of neonates born by mothers diagnosed with syphilis, it is recommended to implement the following tests:

- RPR/VDRL, TPPA/TPHA, Treponema Pallidum IgM antibodies in the blood,

- Complete blood count, liver function tests,

- Electrolyte concentration,

- Cerebrospinal fluid (CSF): pleocytosis, protein concentrations, RPR/VDRL, TPHA/TPPA,

- Long bones X-ray,

- Ophthalmological consultation.
- Crystalline penicillin in $150000 \mathrm{lU} / \mathrm{kg}$ of body weight intravenous injections ( 6 doses every $4 \mathrm{~h}$ ) for 10-14 days; - Benzathine penicillin G in $50000 \mathrm{lU} / \mathrm{kg}$ of body weight intramuscular injections up to the maximum dose of 2.4 million IU;

$-2^{\text {nd }}$ line of treatment is procaine penicillin in 50000 IU/kg of body weight daily intramuscular injections for 10-14 days, if benzathine penicillin G is unavailable;

- In case of positive serological tests in infants or infants whose mothers had seropositive results at the time of childbirth, it is recommended to perform a non-treponemal test every $2-3$ months until a negative result or at least a 4-fold decrease in titre is obtained [27, 28];

- In newborns whose titre does not decrease 4-fold from baseline or increase after the age of 6-12 months, diagnostic and parenteral treatment with benzyl penicillin is recommended for 10 days;

- For positive non treponemal test results in children $>18$ months of age, the untreated infants should be diagnosed with congenital syphilis requiring complete diagnosis and treatment. Children with negative test results at the age of 18 months can be considered as uninfected and do not require further testing or treatment [27, 28];

- Infants with cerebrospinal fluid abnormalities: lumbar puncture every 6 months until normalized results are obtained;

- Positive VDRL reactions from PMR specimens or other abnormalities in the results justify the repetition of treatment due to a suspicion of neurosyphilis (after the elimination of co-morbid conditions) [27, 28];

- Exclusion of maternally acquired HIV in infants;

- Control of the baby up to 18 months for complete exclusion of the congenital infection of Treponema pallidum.

In conclusion, even at the beginning of the $21^{\text {st }}$ century, syphilis constitutes a challenge to gynaecologists, paediatricians, venerologists and dermatologists. All pregnant women are recommended to perform a screening syphilis test during their first prenatal appointment at 7-8 weeks of gestation and at 33-37 weeks of gestation. What is more, neonates born by women with positive serum reaction tests should be administered benzathine penicillin $\mathrm{G}$ in $50000 \mathrm{lU} / \mathrm{kg}$ of body weight intramuscular injections. It is crucial to assess syphilis relapse which is based on the clinical and serum reaction presentation assessment in the $1^{\text {st }}, 3^{\text {rd }}, 6^{\text {th }}$, and $12^{\text {th }}$ month of life.

\section{Conflict of interest}

The authors declare no conflict of interest.

\section{References}

1. Peeling RW, Hook EW. The pathogenesis of syphilis: the Great Mimicker, revisited. J Pathol 2006; 208: 224-32.

2. Ficarra G, Carlos R. Syphilis: the renaissance of an old disease with oral implications. Head Neck Pathol 2009; 3: 195-206. 
3. Kent ME, Romanelli F. Reexamining syphilis: an update on epidemiology, clinical manifestations, and management. Ann Pharmacother 2008; 42: 22-36.

4. Newman L, Kamb M, Hawkes S, et al. Global estimates of syphilis in pregnancy and associated adverse outcomes: analysis of multinational antenatal surveillance data. PLoS Med 2013; 10: e1001396.

5. Majewski S, Rudnicka I. Sexually transmitted diseases in Poland in 2011. Przegl Epidemiol 2013; 67: 283-6.

6. European Centre for Disease Prevention and Control: Sexually transmitted infections in Europe 2012, ECDC, Stockholm 2013.

7. Minister of Health regulation on medical management standards in providing health services of antenatal care for women in the course of physiological pregnancy, physiological delivery, childbirth and neonate care $-20^{\text {th }}$ September 2012.

8. Palfi Z, Ponyai K, Varkonyi V, et al. Primary syphilis on the finger. Dermatology 2008; 217: 252-53.

9. Domantay-Apostol GP, Handog EB, Gabriel MTG. Syphilis: the international challenge of the great imitator. Dermatol Clin 2008; 26: 191-202.

10. Karlińska-Jachowska M, Chmielnicki P, Dziankowska-Bartkowiak B, et al. Syphilis - issue of the 21st century. Postep Dermatol Alergol 2007; 24: 233-7.

11. Janier M, Hegyi V, Dupin N, et al. 2014 European guideline on the management of syphilis. Przegl Dermatol 2015; 102: 459-75.

12. Doroshenko A, Sherrard J, Pollard AJ. Syphilis in pregnancy and the neonatal period. Int J STD AIDS 2006; 4: 221-7.

13. Donders GG. Management of genital infections in pregnant women. Curr Opin Infect Dis 2006; 19: 55-61.

14. Jakubowicz O, Żaba R, Czarnecka-Operacz M. Serological tests for syphilis performed in the Sexually Transmitted Diseases Diagnostic Laboratory in Poznań in 2005-2009. Postep Dermatol Alergol 2010; 27: 275-81.

15. Pastuszczak M, Wojas-Pelc A. Current standards for diagnosis and treatment of syphilis: selection of some practical issues, based on the European (IUSTI) and U.S. (CDC) guidelines. Postep Dermatol Alergol 2013; 30: 203-10.

16. Jakubowicz O, Żaba R, Czarnecka-Operacz M. Serological tests for syphilis performed in the Sexually Transmitted Diseases Diagnostic Laboratory in Poznań between 2000-2004. Postep Dermatol Alergol 2011; 31: 30-5.

17. Ballard R, Hook EW III. Syphilis. In: Laboratory diagnosis of sexually transmitted infections, including human immunodeficiency virus. Unemo M, Ballard R, Ison C, et al. (eds.). World Health Organization (WHO), Geneva, Switzerland 2013; 107-29.

18. Müller H, Eisendle K, Bräuninger W, et al. Comparative analysis of immune-histochemistry, polymerase chain reaction and focus-floating microscopy for the detection of Treponema pallidum in mucocutaneous lesions of primary, secondary and tertiary syphilis. Br J Dermatol 2011; 165: 50-60.

19. Hunter M, Robertson PW, Post JJ. Significance of isolated reactive treponemal chemiluminescence immunoassay results. J Infect Dis 2013; 207: 1416-23.

20. Binnicker MJ, Jespersen DJ, Rollins LO. Treponema-specific tests for serodiagnosis of syphilis: comparative evaluation of seven assays. J Clin Microbiol 2011; 49: 1313-7.

21. Busse C, Navid MH, Strubel A, Schnitzler P. Evaluation of a new recombinant antigen-based Virotech Treponema pallidum screen ELISA for diagnosis of syphilis. Clin Lab 2013; 59: 523-9.
22. Park IU, Chow JM, Bolan G, et al. Screening for syphilis with the treponemal immunoassay: analysis of discordant serology results and implications for clinical management. J Infect Dis 2011; 204: 1297-304.

23. Janier M, Hegyi V, Dupin N, et al. 2014 European guideline on the management of syphilis. J Eur Acad Dermatol Venereol 2014; 12: 1581-93.

24. Serwin A, Majewski S, Żaba R, et al. Diagnostyka i leczenie kity w Europie - stanowisko Grupy Ekspertów Polskiego Towarzystwa Dermatologicznego. Przegl Dermatol 2015; 102: 476-8.

25. Kamb ML, Newman LM, Riley PL, et al. A road map for the global elimination of congenital syphilis. Obstet Gynecol Int 2010; 2010: 312798.

26. Herremans T, Kortbeek L, Notermans DW. A review of diagnostic tests for congenital syphilis in newborns. Eur J Clin Microbiol Infect Dis 2010; 29: 495-501.

27. American Academy of Pediatrics. Syphilis. In: Red Book: 2012 Report of the Committee on Infectious Diseases. 29 ${ }^{\text {th }}$ edn. Pickering LK (ed.). Elk Grove Village, IL, American Academy of Pediatrics 2012; 690-703.

28. Workowski KA, Berman S; Centers for Disease Control and Prevention. Sexually transmitted diseases treatment guidelines, 2010. MMWR 2010; 59: 1-110. 